\title{
Decoloration of wine and subsequent enzymatic quantification of histamine
}

\author{
Markus Lacorn ${ }^{1}$, Ronald Niemeijer ${ }^{1}$, Stella Lindeke ${ }^{1}$, Guillermo Rodríguez ${ }^{2}$, Ana Hernández ${ }^{2}$, Ana Ruano ${ }^{2}$, Jorge \\ Muñoz ${ }^{2}$, and Gilbert Garrido ${ }^{1}$ \\ ${ }^{1}$ R-Biopharm AG, 64297 Darmstadt, Germany \\ ${ }^{2}$ Laboratorio Arbitral Agroalimentario (MAGRAMA), Aguarón, 1328023 Madrid, Spain
}

\begin{abstract}
We would like to present a simple decoloration procedure for (red) wine and the subsequent enzymatic method for the specific quantification of histamine. The test kit for sample preparation contains three solutions that are used to decolorate wine by two simple precipitation steps within $15 \mathrm{~min}$. The enzymatic test kit consists of a microtiter plate coated with two substrates and ready to use reagents (buffer, calibrators and enzyme histamine dehydrogenase). The determination is performed within $15 \mathrm{~min}$ and the measurement wavelength is $450 \mathrm{~nm}$ which is the common wavelength for ELISA procedures. The linear range is from 1 to $20 \mathrm{mg} / \mathrm{L}$ in the extracted sample (corresponding to $2.4-48 \mathrm{mg} / \mathrm{L}$ in wine) and the recovery is $>85 \%$ in red wines and more than $90 \%$ in white and rose wines. The limit of quantification is calculated to $1 \mathrm{mg} / \mathrm{L}$. Wines at this low histamine levels showed CVs of less than 7\%. The assay shows a high precision with a relative within-lab reproducibility standard deviation of less than 7\%. A method comparison between HPLC and the new enzymatic system revealed a very high degree of agreement. The enzymatic procedure contains no dilution steps, no washing steps like for an ELISA, and a clear defined end-point of the enzymatic reaction.
\end{abstract}

\section{Introduction}

Histamine can be produced in wine as a result of bacterial decarboxylation of histidine. While low concentrations of histamine are involved in local immune responses as well as regulating physiological processes, uptake of high concentrations of histamine can cause toxicological effects like migraine headaches and allergic reactions. Histamine is mostly found in red wines at levels between $0.5 \mathrm{mg} / \mathrm{L}$ up to $26.9 \mathrm{mg} / \mathrm{L}$ [1]. Since different recom-mendations for concentrations of histamine in wine exist and the worldwide discussion about a practicable legal threshold is still ongoing, there is a permanent need for analysis with a simple and robust extraction method and a quantification characterized by a high precision. Current methods for analysis of histamine are HPLC, ELISA, and fluorimetry which sometimes require sophisticated instrumentation and in consequence skilled technicians. We would like to present a new enzymatic method for the specific quantification of histamine in red and white wine consisting of a coated microtiter plate and ready-to-use reagents. To remove interfering substances (e.g. polyphenols and anthocyanins) from wine sample a special decoloration test kit is used.

\section{Experimental}

\subsection{Reagents}

\subsubsection{Wine samples}

36 commercial red, rose and white wines from 9 different countries were purchased from a local wholesaler. The selection consists of 18 red wines, 5 dry white wines, 3 sweet white wines and 10 rose wines. More information about red wines is given in Table 4.

\subsubsection{Reagents}

For sample preparation the test kit RIDA $^{\circledR}$ Sample Decolorant (Art. No. R1699, Darmstadt, Germany) was used while for the subsequent enzymatic determination of histamine, the test kit RIDASCREEN ${ }^{\circledR}$ Histamin (enzymatic) from R-Biopharm AG (Art. No. R1605) was taken.

\subsection{Sample preparation}

Due to interfering substances as e.g. polyphenols, a direct determination of histamine in wine is not possible with the enzymatic system at the moment. Generally, an extraction by the aid of a cation exchanger is possible [2] since histamine is positively charged over a broad $\mathrm{pH}$ range but these columns are very expensive.

The test kit used for sample preparation consists of three solutions. $400 \mu \mathrm{L}$ of wine are mixed with $200 \mu \mathrm{L}$ of a buffer (reagent 1) and subsequently treated with $200 \mu \mathrm{L}$ of a decolorant (reagent 2) to precipitate interfering components. After incubation for $5 \mathrm{~min}$ the sample is centrifuged at $14000 \mathrm{~g}$ for $2 \mathrm{~min}$. $500 \mu \mathrm{L}$ of the clear and nearly colorless supernatant are transferred into a clean vial and $100 \mu \mathrm{L}$ of a precipitant (reagent 3 ) are added. After 5 min of incubation the solution is centrifuged at $14000 \mathrm{~g}$ for 2 min the clear supernatant is used for subsequent enzymatic analysis. The test kit components are sufficient for decoloration of 200 wine samples. 


\subsection{Enzymatic analysis}

The test kit consists of a microtiter plate coated with an electron carrier and a dye. Furthermore the kits contain a buffer, the calibrators $(0,1,5,10,15,20 \mathrm{mg} / \mathrm{L})$ and the enzyme solution (histamine dehydrogenase) which are all ready to use. For evaluation of recovery, a spiking solution is also included.

Insert a sufficient number of microtiter wells in the microwell holder for all calibrators and samples to be run in duplicate. Add $150 \mu \mathrm{L}$ of buffer into each well and pipette $100 \mu \mathrm{L}$ of calibrators or samples. Shake and measure absorption 1 at $450 \mathrm{~nm}$ using a microtiter plate reader. Add $10 \mu \mathrm{L}$ of enzyme solution with a multistep pipette, shake, and read absorption 2 at $450 \mathrm{~nm}$ after $10 \mathrm{~min}$. For customer convenience, a special software (RIDA ${ }^{\circledR}$ SOFT Win.net, Art. No. Z9996, R-Biopharm AG, Germany) is available for calculating of concentrations and to evaluate the performance of the user by e.g. a residual plot.

\subsection{Validation parameters}

The following parameters were investigated to characterize the performance of the system: linearity, side chain reactions, limit of detection (LoD) and quantification (LoQ), repeatability, within-laboratory reproducibility, trueness and recovery.

\subsection{Reference method: HPLC}

The HPLC method OIV-MA-AS315-18 was used. It is based on formation of an OPA derivative of histamine detected by FLD (ex/em $340 \mathrm{~nm} / 420 \mathrm{~nm}$ ). The pre-column derivatization is performed by an autosampler and the analytical column used is Kromasil 100-3.5 C-18. Before injection samples are filtered at $0.45 \mu \mathrm{m}$.

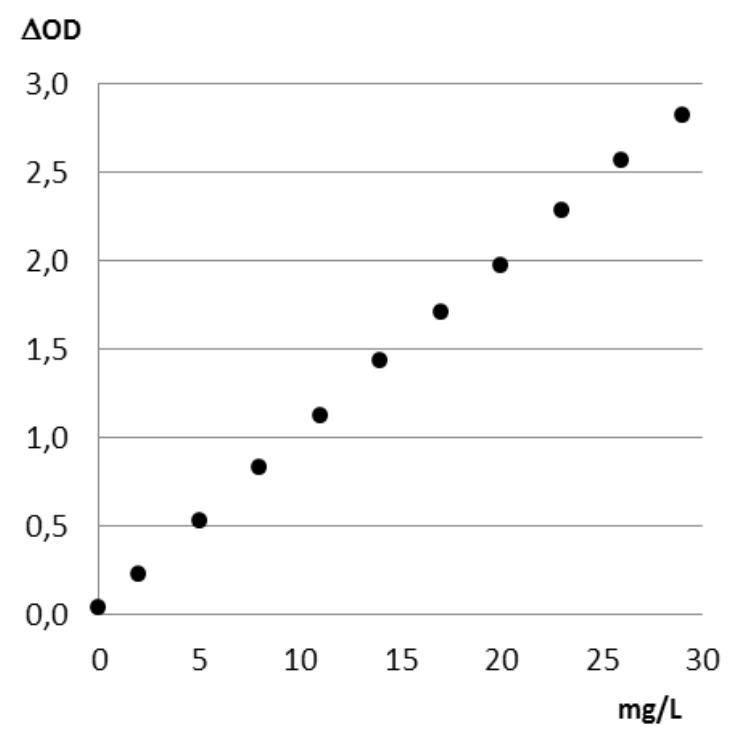

Figure 1. Linearity from $0 \mathrm{mg} / \mathrm{L}$ up to $29 \mathrm{mg} / \mathrm{L}$.

\section{Results and discussion}

\subsection{Linearity and residuals}

There is only a slight tendency to non-linearity above $20 \mathrm{mg} / \mathrm{L}$. Fig. 1 shows the calibration graph between 0 and $29 \mathrm{mg} / \mathrm{L}$. A more precise view on linearity is given in Fig. 2 where a residual plot is presented. A residual is the difference between the measured $\Delta \mathrm{OD}$ value and the theoretical $\Delta \mathrm{OD}$ calculated form the calibration graph between 0 and $20 \mathrm{mg} / \mathrm{L}$.

It is obvious that at concentration near to $30 \mathrm{mg} / \mathrm{L}$ the linearity is not any longer sufficient due to very high $\Delta \mathrm{OD}$ values of more than 2.5 . Optical density values for absorption 1 are well below 0.1 for calibrators and sample extracts. A well-trained technician is able to decrease his residuals down to 0.02 .

\subsection{Side chain activities}

The enzymatic determination is specific for histamine. There are no side reactions to L-histidine, L-tryptophan, serotonin, L-tyrosine, tyramine, L-lysine, and trimethyl-amine. A small side activity of less than $0.4 \%$ was observed for cadaverine, putrescine, spermidine and spermine. However, the signal is so small that it has only a minor impact on the test result. As an example, a content of $50 \mathrm{mg}$ putrescine per $\mathrm{L}$ will result in a histamine signal of not more than $0.2 \mathrm{mg} / \mathrm{L}$.

\subsection{Limits of detection and quantification}

Due to the high sensitivity of the enzymatic system it was not possible to obtain blank samples in a sufficient number to calculate the limit of detection (LoD) for red wines. As an alternative, a calibration graph between 0 and $2 \mathrm{mg} / \mathrm{L}$ (increments $0.2 \mathrm{mg} / \mathrm{L}$ ) was used for estimation of LoD. According to DIN 32645, the LoD was calculated to $0.15 \mathrm{mg} / \mathrm{L}$ in extracts or (including the sample preparation dilution factor

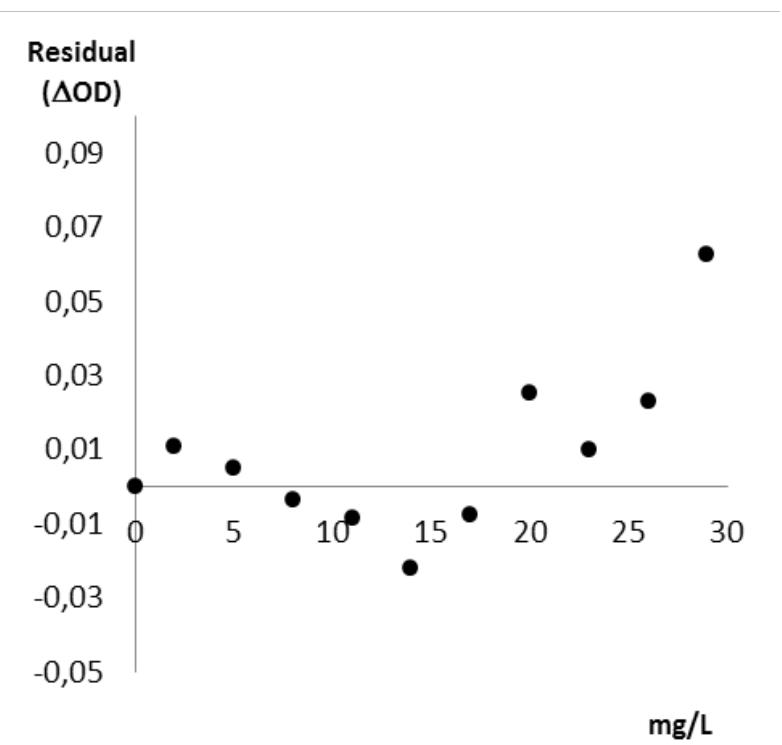

Figure 2. Residual plot from $0 \mathrm{mg} / \mathrm{L}$ up to $29 \mathrm{mg} / \mathrm{L}$. 
Table 1. Within-lab reproducibility of wine samples with histamine concentration near to LoQ $(n=6)$.

\begin{tabular}{lccc}
\hline Wine & mean & SD & CV \\
\hline & $\mathbf{m g} / \mathbf{L}$ & $\mathbf{m g} / \mathbf{L}$ & $\%$ \\
\hline white & 0,77 & 0,04 & 4,8 \\
rose & 0,85 & 0,06 & 6,7 \\
red & 1,11 & 0,07 & 6,2 \\
\hline
\end{tabular}

of 2.4) $0.4 \mathrm{mg} / \mathrm{L}$ in wine samples. The limit of quantification was $0.4 \mathrm{mg} / \mathrm{L}$ and $0.8 \mathrm{mg} / \mathrm{L}$, respectively. Table 1 shows the results for wine samples near to the LoQ of the method.

\subsection{Repeatability}

Four red wines were chosen to cover the lower analytical range between $3.5 \mathrm{mg} / \mathrm{L}$ and $14.5 \mathrm{mg} / \mathrm{L}$ (Table 2).

All samples were extracted and subsequently analysed in the enzymatic assay. The experiment is repeated four times by the same analyst on different days (Table 2). There was a time shift of 4 weeks between day 1 and day 5. The data clearly show that neither the extraction step nor the enzymatic determination is a great source of variability.

\subsection{Within-lab reproducibility}

Five red wine samples were chosen to cover the analytical range between LoQ and $9 \mathrm{mg} / \mathrm{L}$. All samples were extracted six-fold and subsequently analysed in the enzymatic assay by three different persons on different days (Table 3).

As expected the variation between persons was as high as the variation for one person on five different days. To be as realistic as possible we choose persons that are familiar with pipettes and normal laboratory procedures but not familiar with this enzymatic system and the special kind of sample preparation test kit.

\subsection{Trueness}

Using the OIV reference method, a method comparison was performed. More than 20 different red wines were analysed in parallel (Fig. 3).

Table 2. Determination of repeatability for red wine samples within the range of quantification.

\begin{tabular}{cccccccccc}
\hline \multicolumn{2}{c}{ Day 1 } & \multicolumn{2}{c}{ Day 2 } & \multicolumn{2}{c}{ Day 3 } & \multicolumn{2}{c}{ Day 4 } & \multicolumn{2}{c}{ Day 5 } \\
\hline 3.8 & 3.6 & 3.4 & 3.5 & 3.1 & 3.2 & 3.5 & 3.3 & 3.5 & 3.5 \\
5.1 & 5.2 & 4.9 & 5.0 & 5.0 & 4.7 & 4.8 & 4.9 & 5.0 & 5.0 \\
9.5 & 9.6 & 9.4 & 9.5 & 9.2 & 9.2 & 9.3 & 9.3 & 9.4 & 9.5 \\
14.8 & 14.6 & 14.6 & 14.7 & 14.3 & 14.0 & 14.5 & 14.6 & 14.6 & 14.6 \\
\hline Mean & SD & CV & & & & & & & \\
mg/L & mg/L & $\%$ & & & & & & & \\
\hline 3.45 & 0.21 & 6.1 & & & & & & & \\
4.94 & 0.14 & 2.8 & & & & & & & \\
9.37 & 0.13 & 1.4 & & & & & & & \\
14.53 & 0.22 & 1.5 & & & & & & &
\end{tabular}

Table 3. Determination of within-lab reproducibility for red wine samples within the range of quantification.

\begin{tabular}{lllllll}
\hline & \multicolumn{3}{c}{ Analyst 1 } & \multicolumn{2}{c}{ Analyst 2 } & \multicolumn{2}{c}{ Analyst 3 } \\
\hline Wine & $\begin{array}{l}\text { Mean } \\
(\mathrm{mg} / \mathrm{L})\end{array}$ & $\begin{array}{l}\mathrm{CV} \\
(\%)\end{array}$ & $\begin{array}{l}\text { Mean } \\
(\mathrm{mg} / \mathrm{L})\end{array}$ & $\begin{array}{l}\mathrm{CV} \\
(\%)\end{array}$ & $\begin{array}{l}\text { Mean } \\
(\mathrm{mg} / \mathrm{L})\end{array}$ & $\begin{array}{l}\mathrm{CV} \\
(\%)\end{array}$ \\
\hline 1 & 8.83 & 0.7 & 8.89 & 0.8 & 8.79 & 1.0 \\
2 & 5.96 & 0.8 & 5.74 & 2.1 & 5.75 & 1.5 \\
3 & 3.68 & 1.3 & 3.50 & 1.3 & 3.59 & 3.6 \\
4 & 2.02 & 3.1 & 2.04 & 1.5 & 2.00 & 2.3 \\
5 & 1.30 & 5.5 & 1.22 & 3.6 & 1.21 & 4.4 \\
\hline
\end{tabular}

The results clearly show that both method have a high precision and that the trueness of the enzymatic method is given.

\subsection{Recovery}

Some assorted wines from the panel were taken to check for recovery (Table 4). Mainly red wines were used since they always showed at least low histamine levels. The spike level was chosen according to the natural histamine levels of the sample. For control reasons, only one white wine (Riesling) and one rose was additionally spiked. It is obvious that some wines showed recovery rates below $90 \%$.

One German red wine was taken to characterize the recovery at very low spike levels near to LoQ (Table 5). These data indicate that at LoQ levels the recovery may be somewhat lower but still acceptable in means of precision.

\subsection{Wines from the market}

All 18 white and rose wines (dry and sweet) showed concentrations between the LoD and $2 \mathrm{mg} / \mathrm{L}$. Ten out of these

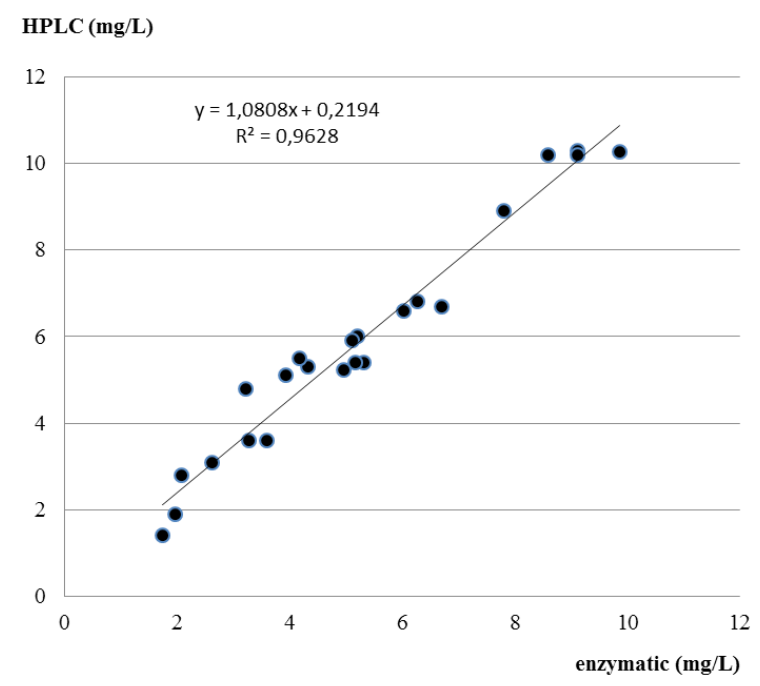

Figure 3. Method comparison between HPLC and the new enzymatic system using 23 different red wines. 
Table 4. Recoveries for white, rose and red wines spiked at different concentrations $(n=2)$ according to their natural contamination.

\begin{tabular}{llllll}
\hline Wine & $\begin{array}{l}\text { unspiked } \\
\mathbf{m g} / \mathbf{L}\end{array}$ & $\begin{array}{c}\mathbf{2} \mathbf{~ m g} / \mathbf{L} \\
\text { rec }(\boldsymbol{\%})\end{array}$ & $\begin{array}{l}\mathbf{5} \mathbf{~ m g} / \mathbf{L} \\
\text { rec }(\boldsymbol{\%})\end{array}$ & $\begin{array}{l}\mathbf{1 0} \mathbf{~ m g / L} \\
\text { rec }(\%)\end{array}$ & $\begin{array}{l}\mathbf{2 0} \mathbf{~ m g / L} \\
\text { rec (\%) }\end{array}$ \\
\hline white & 0.77 & 97 & 93 & 96 & 93 \\
rose & 0.85 & 84 & 91 & 94 & 91 \\
red & 8.8 & & & 89 & 93 \\
red & 5.8 & & & 88 & 88 \\
red & 3.6 & & 90 & 89 & \\
red & 2.0 & & 85 & 91 & \\
red & 1.2 & 86 & 84 & 85 & \\
\hline
\end{tabular}

Table 5. Red wine spiked at very low concentrations $(n=6)$.

\begin{tabular}{lllll}
\hline Spike & $\begin{array}{l}\text { Mean } \\
\mathrm{mg} / \mathrm{L}\end{array}$ & $\begin{array}{l}\text { SD } \\
\mathrm{mg} / \mathrm{L}\end{array}$ & $\begin{array}{l}\text { CV } \\
\%\end{array}$ & $\begin{array}{l}\text { Rec. } \\
\%\end{array}$ \\
\hline $0 \mathrm{mg} / \mathrm{L}$ & 0.78 & 0.04 & 5.3 & - \\
$0.6 \mathrm{mg} / \mathrm{L}$ & 1.24 & 0.05 & 3.7 & 77 \\
$1.0 \mathrm{mg} / \mathrm{L}$ & 1.58 & 0.05 & 3.1 & 80 \\
$1.4 \mathrm{mg} / \mathrm{L}$ & 1.97 & 0.05 & 2.5 & 85 \\
\hline
\end{tabular}

18 wines had values higher than the LoQ of $1 \mathrm{mg} / \mathrm{L}$. Results for red wines are given in Table 6 . It is obvious that the red wines from this selection contain only small amounts of histamine up to $8.59 \mathrm{mg} / \mathrm{L}$. In comparison to the literature, higher amounts of up to $30 \mathrm{mg} / \mathrm{L}$ were expected [1].

It is also interesting to see that some of the red wines from different regions in the world showed amounts near to the calculated LoQ of $1 \mathrm{mg} / \mathrm{L}$.

\section{Outlook and conclusions}

RIDASCREEN ${ }^{\circledR}$ Histamine (enzymatic) is a very userfriendly assay. Results are obtained within a short time. The test kit is robust and gives reliable results that are fit for the purpose.
Table 6. Red wines from different regions and vintages (samples from the market).

\begin{tabular}{llll}
\hline Variety & Vintage & $\mathbf{m g} / \mathbf{L}$ & Region (country) \\
\hline Cuvee & 2008 & 8.59 & Rioja (ES) \\
Syrah & 2011 & 2.21 & Pays d'Oc (F) \\
Plavac mali & 2011 & 4.25 & Dalmatia (CRO) \\
Tempranillo & 2009 & 5.68 & Rioja (ES) \\
Cuvee & 2012 & 2.98 & Corsica (F) \\
Cuvee & 2012 & 3.77 & Castilla (ES) \\
C. Sauvignon & 2010 & 4.04 & Pays d'Oc (F) \\
Sangiovese & 2009 & 2.09 & Chianti (I) \\
Cuvee & 2013 & 5.50 & Puglia (I) \\
Tempranillo & 2008 & 5.36 & Rioja (ES) \\
Cuvee & 2011 & 5.48 & Valpolicella (I) \\
Merlot & 2012 & 2.88 & Pays d'Oc (F) \\
Cuvee & 2008 & 4.84 & Bordeaux (F) \\
Cuvee & 2011 & 1.34 & Beaujolais (F) \\
Zinfandel & 2012 & 1.14 & California (USA) \\
Pinot Noir & 2011 & 2.46 & Baden (D) \\
Pinot Noir & 2013 & 1.24 & Rheingau (D) \\
Pinot Noir & 2009 & 0.94 & Rheingau (D) \\
\hline
\end{tabular}

We would like to thank Diana Daum, Max Sutterlüti, and Bernhard Reck for their practical help and their valuable discussions.

\section{References}

[1] V. Konakovsky, M. Focke, K. Hoffmann-Sommergruber, R. Schmid, O. Scheiner, P. Moser, R. Jarisch, W. Hemmer, Food Add. Contam., 28, 408 (2011)

[2] O. Busto, M. Mestres, J. Guasch, F. Borrull, Chromatographia, 40, 404 (1995)

[3] DIN 32645:2008-11. Chemical analysis - Decision limit, detection limit and determination limit under repeatability conditions - Terms, methods and evaluation. 